\title{
Anti-Epileptic Drug Prescription in a Psychiatric Hospital Outpatient Clinic in Southeast Nigeria
}

\author{
Justin U. Achor ${ }^{1 *}$, Emeka C. Nwefoh ${ }^{2}$, Birinus A. Ezeala-Adikaibe ${ }^{3}$, \\ Chinwe F. S. Ezeruigbo ${ }^{4}$, Aham 0. Agomoh' ${ }^{1}$ \\ ${ }^{1}$ Federal Neuropsychiatric Hospital, Enugu, Nigeria \\ ${ }^{2} \mathrm{CBM}$ International, Abuja, Nigeria \\ ${ }^{3}$ Department of Medicine, University of Nigeria Teaching Hospital, Ituku/Ozalla, Nigeria \\ ${ }^{4}$ Department of Nursing Sciences, Faculty of Health Science, Ebonyi State University, Abakaliki, Nigeria \\ Email: ‘juachor@yahoo.com, ahamagomoh@usa.net, emeka.nwefoh@cbm-arow.org, emekanwefoh.cbmnigeria@gmail.com, \\ nigeriaepilepsy@hotmail.com, chinweezeruigbo@yahoo.com
}

How to cite this paper: Achor, J.U., Nwefoh, E.C., Ezeala-Adikaibe, B.A., Ezeruigbo, C.F.S. and Agomoh, A.O. (2017) AntiEpileptic Drug Prescription in a Psychiatric Hospital Outpatient Clinic in Southeast Nigeria. Open Journal of Psychiatry, 7, 294306.

https://doi.org/10.4236/ojpsych.2017.74025

Received: May 31, 2017

Accepted: August 19, 2017

Published: August 22, 2017

Copyright () 2017 by authors and Scientific Research Publishing Inc. This work is licensed under the Creative Commons Attribution International License (CC BY 4.0).

http://creativecommons.org/licenses/by/4.0/

\begin{abstract}
The optimum control of seizures requires adequate dosing of appropriately selected anti-epileptic medications. The availability of AEDs in Nigeria is limited and this constrains the prescription latitude of clinicians. This study was conducted to describe the prescribing pattern of anti-epileptic drugs in the outpatient service of a psychiatric facility in southeast Nigeria. The case records of the epileptic patients attending the outpatient clinic of a psychiatric hospital were retrieved, reviewed and data abstracted with a prepared proforma. The information extracted include age, sex, marital status, residence, type of seizure and anti-seizure medications prescribed, frequency of administration and dosage among other variables. Of the 178 patients whose prescriptions and case records were assessed, males constituted $62.9 \%$ and females $37.1 \%$. Most of the patients were single (78.1\%) and the group had a mean age of $25.6 \pm 10.9$ years. Generalized tonic-clonic seizures predominated (61.2\%) among the seizure types, whilst complex partial seizure type was identified in $35.4 \%$ of the patients. Patient diagnosis relied heavily on the use of clinical description alone. About $92.7 \%$ of the patients were treated with monotherapy, whereas $7.3 \%$ received two anti-epileptic drug combinations. Carbamazepine was the most frequently prescribed drug, and was utilized in the treatment of $87.9 \%$ of patients receiving monotherapy and $92.3 \%$ of individuals receiving two drug combinations. Adjunctive medications like benzodiazepines were rarely utilised to improve the effect of the AEDs. The patients that received polytherapy could only be distinguished from those that received
\end{abstract}


monotherapy by higher frequency of epileptic auras and higher mean dose of AEDs per day. The predominant use of monotherapy is in accordance with the treatment recommendations and needs to be encouraged. The greater use of carbamazepine is probably related to its perceived benefits in the control of behavioural symptoms.

\section{Keywords}

Epilepsy Treatment, Anti-Epileptic Drug Prescribing, Psychiatric, Nigeria

\section{Introduction}

Epilepsy is one of the major neurological syndromes whose psychological and behavioural manifestations may result in psychiatric presentation, sometimes very early in the illness trajectory. The psychiatric problems associated with epilepsy and their consequences may be the most poignant aspect of the condition [1]. Some epileptic patients may develop various psychiatric syndromes following repeated seizures or the administration of antiepileptic medications [2] [3] [4]. Prevalence studies suggest rates of almost 50\% for psychiatric disorders among epileptic patients [5] [6] [7] and raise the necessity for active psychiatric case finding in epilepsy treatment centres.

The goals of therapy in epilepsy, irrespective of the setting remain to achieve seizure control and improve the patient's quality of life in a cost-effective manner [8] [9]. Even when the seizures cannot be controlled completely, a reduction in their frequency and severity can contribute immensely to enhancing the patient's quality of life and general wellbeing [10] [11] [12]. The rational use of antiepileptic drugs in settings with limited resources necessitate the evaluation and audit of their prescribing patterns in relation to efficacy in seizure control and patient wellbeing enhancement [11] [13]. The assessment and monitoring of care quality is necessary for health system capacity-building, decision-making and policy actions [13] [14]. The drug prescription patterns are related to drug availability, accessibility, and clinician preferences within a given locality. In Nigeria, the availability of anti-epileptic drugs is limited to a few medications for generalized and partial seizures, and this constrains the prescription latitude of the clinicians, notwithstanding their understanding of the spectrum of potential pharmacological agents that could be more appropriate in specific circumstances. However, the choice of medications is also strongly influenced by the perceived efficacy of the prescribed treatment. Optimal seizure control can contribute to the effective management of the psychiatric complications of seizure disorders. On the other hand, the choice of an anti-epileptic drug can exacerbate the psychiatric symptomatology a patient experiences [15].

To our knowledge, there has been no previous study on the anti-epileptic prescription pattern in the setting of a psychiatric hospital practice in the southeastern part of Nigeria. This study was undertaken with a view to helping to 
ameliorate this gap. The aim of this study was to describe the prescribing patterns of anti-epileptic medications within a psychiatric hospital outpatient service.

\section{Methods}

\subsection{Design}

This study had a cross-sectional design with a retrospective conception and focus on the description of the drug prescription practices for treatment of epilepsy in a single psychiatric treatment facility.

\subsection{Setting}

The study was carried out at the Federal Neuropsychiatric Hospital, Enugu. The hospital is a 220 bed specialist psychiatric treatment facility located in Enugu metropolis. The hospital receives referrals from the five eastern states and their environs, especially from inhabitants of the adjoining Niger Delta and North Central geo-political zones.

\subsection{Data Collection}

The study involved the retrieval, review and abstracting of archived data for patients being treated for epilepsy or seizure disorder in Federal Neuropsychiatric Hospital, Enugu. The case records of patients treated in Federal Neuropsychiatric Hospital, Enugu, who had a diagnosis of epilepsy or seizure disorder were retrieved from the Medical Records Department. The retrospective review of patients' charts and prescription orders was undertaken in the course of the study.

All the patients being actively treated for epilepsy or seizure disorder between January and September 2015 were eligible for inclusion in the study. All patients presenting to the hospital for epilepsy or seizure evaluation are first seen in the crisis intervention Unit of the hospital by resident doctors. The attending doctors usually determine whether the patients would be treated as outpatients or inpatients. Thereafter, the patients are discussed with the Consultant Psychiatrist and/or Neurologist in the wards or outpatient clinics for verification, validation or confirmation of the clinical diagnosis according to current diagnostic guidelines. For individuals with concurrent psychiatric conditions, the diagnosis is usually determined according to the ICD 10 guidelines. On the other hand, the seizure presentation is used to provide clinical diagnoses according to the International League Against Epilepsy (ILAE) guidelines.

In practice, the following inclusion criteria were followed: patients being treated for epilepsy or seizure disorder in the outpatient clinic, patients who maintained regular clinic attendance and individuals who were compliant with anti-epileptic medications. The latter information was verified using information in the progress notes. For each of the selected cases, a Consultant Psychiatrist (JUA) and Neurologist (BEA) reviewed the symptoms and signs and chart diagnosis before their inclusion in the study. The epilepsy diagnosis of each included patient was reviewed, confirmed or validated by the neurologist on the basis of 
the chart documented clinical data using the ILAE classification system. On the other hand, the patients' psychiatric diagnoses were reviewed or validated by the psychiatrist (JUA) using the ICD-10 diagnostic criteria.

Patients who were no longer attending the outpatient clinics or had stopped their anti-epileptic medications were excluded. Also excluded were patients who had frequent missed appointments, those whose compliance with medication was poor, and those whose seizures occurred in the context of complex medical presentation (e.g. diabetes, stroke, and HIV/AIDS). Patients were also excluded if their case files lacked complete documentation of clinical data or relevant sociodemographic details.

For the selected patients, the clinical notes and prescription orders were reviewed for abstraction of the relevant data. The relevant data were collected using a pre-designed proforma. The information extracted include age, sex, marital status, residence, type of seizure, duration of disease, and anti-epileptic medications prescribed (including frequency of administration and daily dosage). We converted the dosage of each of the medications to the carbamazepine equivalent.

\subsection{Data Analysis}

Data analysis was undertaken using SPSS version 15. The analysis involved the determination of frequencies, rates as well as measures of central tendency and dispersion for variables of interest like type of anti-epileptic medication, pattern of AED prescription and duration of seizures, among others. Bivariate relationships between variables were explored using chi squared tests for group comparisons and ANOVA for determination of differences in means. The level of statistical significance was set at $p<0.05$.

\section{Results}

\subsection{Sample Characteristics}

One hundred and seventy eight patients consisting of 112 males (62.9\%) and 66 females (37.1\%) were studied. The majority of the patients (78.1\%) were single and the sample had a mean age of $25.6 \pm 10.9$ years (Range: $9-60$ years). The median age was 25.0 years. Table 1 shows the descriptive characteristics of the sample. The majority of the patients $(71.9 \%)$ attended the clinics from rural areas whereas $28.1 \%$ resided in the cities.

\subsection{Clinical Characteristics of the Patients}

The mode of assessment of the patients was mostly by use of clinical evaluation alone (90.4\%). The EEG was utilized in $6.7 \%$, CT scan in $2.2 \%$ whereas MRI was utilised in only one case $(0.5 \%)$ for patient assessment.

The majority of the patients denied any family history of epilepsy or mental illness. Only $9.0 \%$ admitted to either a family history of epilepsy or mental illness. Also, only a minority of the patients (6.2\%) admitted to having suffered a 
Table 1. Demographic characteristics of the patients.

\begin{tabular}{ccc}
\hline \multirow{2}{*}{ Demographic Characteristic } & Number (N) & Percent (\%) \\
\cline { 2 - 3 } Sex & $\mathbf{N}=178$ & 100.0 \\
Male & 112 & 62.9 \\
Female & 66 & 37.1 \\
Age (Years) & & \\
Mean & 25.6 & \\
S.D & 10.9 & \\
Median & 25.0 & \\
Range & $9-60$ & \\
Marital Status & & 78.1 \\
Single & 139 & 18.0 \\
Married & 32 & 2.2 \\
Divorced/Separated & 3 & 71.9 \\
Widowed & 50 & \\
Place of Residence & 128 & \\
Urban & & \\
Rural & & \\
\hline
\end{tabular}

mental disorder in the past. With regard to the seizure type 109 (61.2\%) of the patients presented with generalized tonic-clonic seizures whereas 63 (35.4\%) had complex partial seizures. About one-third of the patients (32.0\%) reported having an aura before each seizure episode. In $3.9 \%$ of the patients the EEG and imaging modalities showed evidence of focal brain lesions. Table 2 depicts the clinical characteristics of the patients.

\subsection{Seizure Management Strategy}

One hundred and sixty five of the 178 patients (92.7\%) were treated with antiepileptic drug monotherapy whereas $13(7.3 \%)$ received two-drug combinations. There were no individuals that were treated with more than two anti-epileptic drugs. Table 3 shows the pattern of anti-epileptic drug prescription in the setting.

Among the patients on monotherapy, carbamazepine was the most frequently prescribed drug: $87.9 \%$ of the patients on monotherapy received carbamazepine. The other patients received sodium valproate (8.5\%), phenobarbitone (1.7\%), and phenytoin (1.7\%). Of the patients treated with two anti-epileptic drugs, $76.9 \%$ received carbamazepine and phenobarbitone, $15.4 \%$ carbamazepine and valproate combination, and $7.7 \%$ received phenobarbitone and phenytoin combination. The patients on monotherapy had a mean age of $27.0 \pm 11.5$ years, 
Table 2. Clinical characteristics of the patients.

\begin{tabular}{ccc}
\hline Clinical Characteristic & Number (N) & Percent (\%) \\
\hline Mode of assessment & 161 & 90.4 \\
Clinical only & 12 & 6.7 \\
EEG $^{*}$ & 4 & 2.2 \\
CT $^{* *}$ & 1 & 0.5 \\
MRI** & & \\
Seizure Type & 109 & 61.2 \\
Generalized Seizures & & \\
Partial Seizures & 3 & 3.7 \\
Simple Partial Seizures & 63 & 1.7 \\
Complex Partial Seizures & 3 & \\
Partial Seizures with Secondary generalization & & 4.5 \\
Miscellaneous & 8 & 4.5 \\
Family history of Epilepsy & 8 & 6.2 \\
Family history of mental illness & 11 & 3.9 \\
Past History of mental illness & 7 & \\
Presence of focal brain lesions & & \\
\hline
\end{tabular}

${ }^{\star} \mathrm{EEG}=$ Electroencephalography; ${ }^{* *} \mathrm{CT}=$ Computerised Tomography Scan; ${ }^{* *} \mathrm{MRI}=$ Magnetic Resonance Imaging.

Table 3. Pattern of Anti-Epileptic Drug (AED) prescription.

\begin{tabular}{|c|c|c|}
\hline Pattern of AED Use & Number (N) & Percent (\%) \\
\hline Seizure Management Strategy & $\mathrm{N}=178$ & $100 \%$ \\
\hline Monotherapy & 165 & 92.7 \\
\hline Polytherapy & 13 & 7.3 \\
\hline Drugs used for Monotherapy & $\mathrm{N}=165$ & \\
\hline Carbamazepine (CBZ) & 145 & 87.9 \\
\hline Valproate (Valp) & 14 & 8.5 \\
\hline Phenobarbitone (PHE) & 3 & 1.7 \\
\hline Phenytoin (PHT) & 3 & 1.7 \\
\hline Pattern of Polytherapy & $(\mathrm{N}=13)$ & \\
\hline Use of 2 drugs & 13 & 100.0 \\
\hline Use of 3 drugs & 0 & 0.0 \\
\hline \multicolumn{3}{|l|}{ Drugs used for Polytherapy } \\
\hline $\mathrm{CBZ}+\mathrm{VALP}$ & 2 & 15.4 \\
\hline $\mathrm{PHE}+\mathrm{PHT}$ & 1 & 7.7 \\
\hline $\mathrm{CBZ}+\mathrm{PHE}$ & 10 & 76.9 \\
\hline \multicolumn{3}{|l|}{ Adjunct Medications } \\
\hline \multicolumn{3}{|l|}{ Benzodiazepines } \\
\hline Diazepam & 2 & 1.1 \\
\hline Clonazepam & 11 & 6.2 \\
\hline Vinpocetine & 3 & 1.7 \\
\hline Donepexil & 2 & 1.1 \\
\hline
\end{tabular}


whereas those that received polytherapy had a mean age of $23.4 \pm 8.6$ years ( $p>$ $0.05)$. There were no differences in the type of seizures presented with and the duration of the illness between those that received AED polytherapy in comparison with individuals on monotherapy. On the other hand, statistically significant differences were observed in the frequency of reporting of aura in the periictal period and daily dosage of anti-epileptic drugs prescribed for individuals in the two groups. There was a higher rate of reporting of epileptic aura in the polytherapy group relative to the monotherapy group (69.2\% versus $29.1 \%)(p=$ $0.003)$. In addition, individuals on polytherapy received much higher mean daily medication doses $(p<0.0001)$. The dosing of anti-epileptic medications and selected seizure variables in the two groups (monotherapy versus polytherapy) are depicted in Table 4.

Some of the patients received certain medications as adjuncts to their AED medications, either to improve control of seizures or to enhance cognitive functioning. Some of the medications prescribed as adjuncts in this manner include clonazepam (6.2\%), diazepam (1.1\%), vinpocetine (1.7\%), and donepexil (1.1\%).

Table 4. Seizure variables and dosing of the medications.

\begin{tabular}{|c|c|c|c|}
\hline Seizure Variable & $\begin{array}{l}\text { Patients on } \\
\text { Monotherapy } \\
\mathrm{N} \text { (percent) }\end{array}$ & $\begin{array}{l}\text { Patients on } \\
\text { Polytherapy } \\
\mathrm{N} \text { (percent) }\end{array}$ & $\begin{array}{c}\text { Statistical } \\
\text { analysis } \\
P \text {-value }\end{array}$ \\
\hline \multicolumn{4}{|c|}{ Duration of Seizure (Years) } \\
\hline Mean & 10.9 & 10.3 & \multirow{3}{*}{$\begin{array}{l}\mathrm{F}=0.41 \\
p=0.839\end{array}$} \\
\hline S. D & 10.4 & 5.6 & \\
\hline Median & 8.0 & 10.0 & \\
\hline \multicolumn{4}{|l|}{ Seizure type } \\
\hline Generalized & $100(60.6 \%)$ & $9(69.2 \%)$ & \multirow{3}{*}{$\begin{aligned} X^{2} & =0.704 \\
p & =0.703\end{aligned}$} \\
\hline Complex Partial & $59(35.8 \%)$ & $4(30.8 \%)$ & \\
\hline $\begin{array}{l}\text { Partial seizure alone or } \\
\text { secondarily generalized }\end{array}$ & $6(3.6 \%)$ & $0(0.0 \%)$ & \\
\hline \multicolumn{4}{|c|}{ Presence of Aura before Seizure } \\
\hline Yes & $48(29.1 \%)$ & $9(69.2 \%)$ & \multirow{2}{*}{$\begin{aligned} X^{2} & =8.919 ; \\
p & =0.003\end{aligned}$} \\
\hline No & $117(70.9 \%)$ & $4(30.8 \%)$ & \\
\hline \multicolumn{4}{|l|}{ Medication Daily Dose } \\
\hline Mean & 562.12 & 1207.69 & \multirow{3}{*}{$\begin{array}{c}\mathrm{F}=70.291 \\
p=0.000\end{array}$} \\
\hline S. D & 247.00 & 462.71 & \\
\hline Median & 400.00 & 1200.00 & \\
\hline \multicolumn{4}{|l|}{ Frequency of AED Dosing } \\
\hline Mean & 2.07 & 2.15 & \multirow{3}{*}{$\begin{array}{l}\mathrm{F}=0.538 \\
p=0.464\end{array}$} \\
\hline S. D & 0.42 & 0.38 & \\
\hline Median & 2.00 & 2.00 & \\
\hline
\end{tabular}




\section{Discussion}

The major finding of this study was the predominant use of monotherapy as a treatment strategy for epilepsy patients seen in the psychiatric facility. This practice is in accordance with the recent treatment recommendations and expert guidelines [13] [16] [17] [18] and needs to be encouraged. There appears to be a general trend towards the reduction of polytherapy and greater use of monotherapy in the prescription patterns of anti-epileptic medications in specialist centres in both the industrialized and developing countries [9] [11] [19] [20] [21]. The major sources of differences appear to be the selection of what monotherapy to prescribe for individual patients. However, some reports have drawn attention to the observation that in some series, polytherapy is being increasingly adopted, as a means of overcoming the refractory nature of some patients' epilepsies [22] [23]. Some of these reports have also shown that the adoption of polytherapy significantly increases the cost of epilepsy treatment. For instance, an Indian study showed that the addition of newer anti-epileptic drugs to overcome difficult to control seizures increased the direct cost of treating epilepsy exponentially [22]. It is not certain as to the extent to which refractoriness will influence the prescription pattern in Nigeria and similar resource limited settings in the future.

The finding of the almost exclusive use of carbamazepine for all categories of seizures might appear to be a peculiarity of the treatment setting. It was prescribed for $92.7 \%$ of the patients that received monotherapy and $92.3 \%$ of the patients that received two anti-epileptic drugs. This high rate of prescription of carbamazepine might be related to its mood stabilizing properties [3] and the control of the behavioural manifestations of epilepsy [24]. It is likely that most of the patients that present to the psychiatric facility with seizure disorders might be those with predominantly complex partial seizures and behavioural concomitants of generalized epilepsy. This view is in keeping with the observation of a seizure phenomenology of $35.4 \%$ for complex partial seizures and $61.2 \%$ for generalized tonic-clonic seizures in the series. The minimal undesirable effects of carbamazepine on cognition and behaviour is noteworthy [25] [26] [27]; however, the current recommendations denote it as one of the first line drugs for partial and secondarily generalized epilepsies [16] [28], a status it shares with sodium valproate, lamotrigine, and oxcarbazepine. It is therefore not clear whether the observed near reliance on the use of carbamazepine for seizure disorders encountered in psychiatric practice constitutes an appropriate use of the drug. It is also not clear what level of seizure control was achieved for most of the patients that were given this treatment or the quality of their lives. Further studies might be required to evaluate these issues. On the other hand, in the psychiatric treatment of epileptic disorders, the achievement of seizure control with a medication that does not provoke or exacerbate psychiatric and emotional symptoms is given premium value [3] [15] [29].

The rate of prescription of sodium valproate observed in this study $(8.5 \%)$ 
appears rather low, given that it is also thought to have mood stabilizing effects [27] and is recommended as a drug of choice for primary generalized seizures and in situations in which the seizure type is uncertain [16]. These characteristics make it suitable for use in specialist psychiatric treatment of epilepsy. However, Lim et al. have cautioned that the availability and accessibility of antiepileptic drugs play crucial roles in their use by clinicians, especially in the developing countries [9]. It is not certain if this had contributed to the observed picture. Neither is it clear whether it was the cost or logistical reasons that resulted in the complete absence of use of the newer anti-epileptic drugs like lamotrigine and oxcarbazepine which also appear to be well-tolerated, and stable with respect to mood, cognition and behaviour [18] [27] [30] [31].

The over-reliance on clinical assessments as the sole diagnostic instrument for epileptic disorders observed in this study suggests that our practice lags way behind international recommendations. Although, clinical approaches can suffice in the diagnosis of epilepsy, the judicious use of EEG and neuro-imaging techniques can help improve the quality of epilepsy care [13] [18] [20] and facilitate the detection of those conditions that could be surgically corrected [32] [33]. The use of EEG in the diagnosis of seizures gives valuable information that may create value with respect to clinical diagnostic specification, classification of the epilepsy type, choice of future AED and recognition of structural brain lesions [34]. Unlike EEG, the low rate of usage of CT and MRI assessments is justified because they are only recommended when their attendant costs are justifiable, and especially, for exploration of suspected underlying structural brain lesions [34]. However, in the setting in which the study was conducted, the availability, accessibility and affordability of high technology investigative procedures pose tough logistical obstacles to overcome.

A minority of the patients were treated with diazepam and clonazepam as add-on therapy to improve the efficacy of the prescribed anti-epileptic medications. Even though this practice is widespread [9] [35] [36], it needs not be encouraged because these drugs can cause marked sedation and tolerance when used for just a short period of time. Two of the medications used as adjuncts in this study (vinpocetine and donepezil) were prescribed for individuals who had complained of memory and concentration difficulties. It is not certain if this pattern of usage was appropriate or inappropriate. However, vinpocetine in particular, is being promoted in Nigeria as an agent that can improve cognitive performance, even in normal people and among students engaged in academic pursuits [37]. Even though this represents an exaggerated marketing promise, it is possible that certain clinicians may accept such statements literally.

The usual approach to epilepsy treatment involves riveting attention on the control of the seizures alone. However, treatment in the psychiatric setting requires consideration of the psychological and social impacts of the seizures and their consequences as well [38]. These matters usually affect the decisions regarding what medications to prescribe in given clinical contexts. The appropriate selection and adjustment of anti-epileptic drugs can help to effectively manage 
the behavioural manifestations of epilepsy [39] [40].

\section{Limitations}

The generalisability of the findings of this study is limited by its retrospective cross-sectional design, its use of institutional records with likelihood of incomplete data and perhaps higher risk of data collection errors. However, efforts were made to include only cases whose clinical charts provided the required clinical information and the abstracted data were cross-checked by one of the resident doctors in the Unit. These could have helped to ensure the completeness of the data. It is also not clear to what extent the findings of the study can be representative of the practices of all the psychiatric treatment facilities in the eastern part of Nigeria since the data were collected from a single treatment facility within the region. Nonetheless, within limits, this study has suggested that the treatment of epilepsy in a specialist psychiatric setting accords with the current expert recommendations with regard to selection of effective drugs for seizure control, while making due allowance for the logistical constraints in accessing the newer medications. The findings of the study provide a baseline for undertaking observational studies with a view to elucidating the determinants of the prescription preference of clinicians within resource poor practice settings.

\section{Conclusion}

The treatment of epilepsy with a predominantly monotherapy approach accords with expert recommendations. The greater use of carbamazepine is probably related to its perceived benefits in the control of behavioural symptoms that might accompany epilepsy. It is however not certain whether this drug gives adequate seizure control for the majority of patients. There appears to be an under-utilization of sodium valproate which is reputed to have a broader spectrum of utility than carbamazepine and also exerts mood stabilizing effects. The influence of costs and accessibility in determining the drug prescription preferences observed in this study cannot be easily deciphered. More studies are required to explore the influence of newer drugs on the wellbeing and quality of life of epilepsy patients within the study setting.

\section{References}

[1] Pilo, L. (1993) The Psychiatric Complications of Epilepsy. Singapore Medical Journal, 34, 349-350.

[2] Kanner, A.M. (1999) Depressive Disorders in Epilepsy. Neurology, 53, S26-S32. https://doi.org/10.1212/WNL.53.8.26A

[3] Bresnahan, D. (2004) Psychiatric Comorbidity in Epilepsy and End Stage Renal Disease. Wisconsin Medical Journal, 103, 64-67.

[4] Sander, J.W.A.S., Hart, Y.M., Trimble, M.R. and Shorvon, S.D. (1991) Vigabatrin and psychosis. Journal of Neurology, Neurosurgery, \& Psychiatry, 54, 435-439. https://doi.org/10.1136/jnnp.54.5.435

[5] Kessler, R.C., McGonagle, K.A., Zhao, S., Nelson, C.B., Hughes, M., et al (1994) Lifetime and 12-Month Prevalence of DSM-III-R Psychiatric Disorders in the 
United States: Results from the National Comorbidity Survey. Archives of General Psychiatry, 51, 8-19. https://doi.org/10.1001/archpsyc.1994.03950010008002

[6] Fiordelli, E., Beghi, E., Bogliun, G. and Crespi, V. (1993) Epilepsy and Psychiatric Disturbance: A Cross-Sectional Study. British Journal of Psychiatry, 163, 446-450. https://doi.org/10.1192/bjp.163.4.446

[7] Jones, J.A., Hermann, B.P., Barry, J.J., Gilliam, F., Kanner, A.M. and Meador, K.J. (2005) Clinical Assessment of Axis 1 Psychiatric Morbidity in Chronic Epilepsy: A Multicenter Investigation. The Journal of Neuropsychiatry and Clinical Neurosciences, 17, 172-179. https://doi.org/10.1176/jnp.17.2.172

[8] Tugwell, C. (2003) Current and Future Aspects of the Drug Therapy of Epilepsy. Hospital Pharmacist, 10, 296-302.

[9] Lim, S., Tan, E. and Chen, C. (1997) Pattern of Anti-Epileptic Drug Usage in a Tertiary Referral Hospital in Singapore. Neurology Journal of Southeast Asia, 2, 77-85.

[10] Li, L.M., Fernandes, P.T., Noronha, A.L.A., Marques, L.H.N., Borges, M.A., Borges, K., Cendes, F., Guerreiro, C.A., Zanetta, D.M., de Boer, H.M., Espindola, J., Miranda, C.T., Prilipko, L. and Sander, J.W. (2007) Demonstration Project on Epilepsy in Brazil: Outcome Assessment. Arquivos De Neuro-Psiquiatria, 65, 58-62. https://doi.org/10.1590/S0004-282X2007001000010

[11] Thomas, S.V., Koshy, S., Sudhakaran Nair, C.R. and Sarma, S.P. (2005) Frequent Seizures and Polytherapy Can Impair Quality of Life in Persons with Epilepsy. Neurology India, 53, 46-50. https://doi.org/10.4103/0028-3886.15054

[12] Dourado, M.V., Alonso, N.B., Martins, H.H., Oliveira, A.R.C., Vancini, R.L., de Lima, C., Dubas, J.P., Ferreira Caboclo, L.O., Ferreira Guilhoto, L.M.F. and Yacubian, E.M.T. (2007) Quality of Life and the Self-Perception Impact of Epilepsy in Three Different Epilepsy Types. Journal of Epilepsy and Clinical Neurophysiology, 13, 191-196. https://doi.org/10.1590/S1676-26492007000400009

[13] Bassili, A., Omar, T., Zaki, A., Abdel-Fattah, M., Tognoni, G. and Egyptian-Italian Collaborative Group (2002) Pattern of Diagnostic and Therapeutic Care of Childhood Epilepsy in Alexandria, Egypt. International Journal for Quality in Health Care, 14, 277-284. https://doi.org/10.1093/intqhc/14.4.277

[14] Williamson, J.W. (1994) Issues and Challenges in Quality Assurance of Health Care. International Journal of Quality in Health Care, 6, 5-15. https://doi.org/10.1093/intqhc/6.1.5

[15] Kanner, A.M. (2003) Depression in Epilepsy: Prevalence, Clinical Semiology, Pathogenic Mechanisms, and Treatment. Biological Psychiatry, 54, 388-398. https://doi.org/10.1016/S0006-3223(03)00469-4

[16] Marson, A.G., Appleton, R., Baker, G.A., Chadwick, D.W., Doughty, J., Eaton, B., Gamble, C., Jacoby, A., Shackley, P., Smith, D.F., Tudur-Smith, C., Vanoli, A. and Williamsion, P.R. (2007) A Randomized Controlled Trial Examining the Longer Term Outcomes of Standard Versus New Antiepileptic Drugs. The SANAD Trial. Health Technology Assessment, 11, 1-134. https://doi.org/10.3310/hta11370

[17] Lammers, M.W., Hekster, Y.A., Keyser, A.A., Meinardi, H.H., Renier, W.O. and Van Lier, H. (1995) Monotherapy or Polytherapy for Epilepsy Revisited: A Quantitative Assessment. Epilepsia, 36, 440-446. https://doi.org/10.1111/j.1528-1157.1995.tb00484.x

[18] Scottish Intercollegiate Guidelines Network (2003) Diagnosis and Management of Epilepsy in Adults: A National Clinical Guideline. Scottish Intercollegiate Guidelines Network, Edinburgh, SIGN 70. 
[19] Poindexter, A.R., Berglund, J.A. and Kolstoe, P.D. (1993) Changes in Antiepileptic Drug Prescribing Patterns in Large Institutions: Preliminary Results of a Five Year Experience. American Journal on Mental Retardation, 98, 34-40.

[20] Smith, D., Defalla, B.A. and Chadwick, D.W. (1999) The Misdiagnosis of Epilepsy and the Management of Refractory Epilepsy in a Specialist Clinic. Quarterly Journal of Medicine, 92, 15-23. https://doi.org/10.1093/qjmed/92.1.15

[21] Hui, A.C.F. (2004) Kwan P Epilepsy in Hong Kong: A Literature Review. Hong Kong Medical Journal, 10, 185-189.

[22] Haroon, A., Tripathi, M., Khanam, R. and Vohora, D. (2012) Antiepileptic Drugs Prescription Utilization Behaviour and Direct Costs of Treatment in a National Hospital of India. Annals of Indian Academy of Neurology, 15, 289-293. https://doi.org/10.4103/0972-2327.104338

[23] Malerba, A., Ciampa, C., De Fazio, S., Fattore, C., Frassine, B., La Neve, A., Pellacani, S., Specchio, L.M., Tiberti, A., Tinuper, P. and Perucca, E. (2010) Patterns of Prescription of Antiepileptic Drugs in Patients with Refractory Epilepsy at Tertiary Referral Centres in Italy. Epilepsy Research, 91, 273-282.

https://doi.org/10.1016/j.eplepsyres.2010.08.002

[24] Torta, R. and Keller, R. (1999) Behavioural, Psychotic, and Anxiety Disorders in Epilepsy: Etiology, Clinical Features, and Therapeutic Implications. Epilepsia, 40, S2S20. https://doi.org/10.1111/j.1528-1157.1999.tb00883.x

[25] Waisburg, H. and Alvarez, N. (1998) Carbamazepine in the Treatment of Epilepsy in People with Intellectual Disability. Journal of Intellectual Disability and Research, $42,36-40$.

[26] Sweileh, W., Al-Shakshair, A., Jardarat, N., Abu-Rabie, K. and Sabah, W. (2006) Prevalence and Treatment of Patients with Epilepsy Associated with Intellectual Disability: A Pilot Study in Palestine. The Islamic University Journal, 14, 183-189.

[27] Kwan, P. and Brodie, M.J. (2001) Neuropsychological Effects of Epilepsy and Antiepileptic Drugs. Lancet, 357, 216-222. https://doi.org/10.1016/S0140-6736(00)03600-X

[28] Epilepsy Guidelines Group (2004) Primary Care Guidelines for the Management of Females with Epilepsy. The Royal Society of Medicine Press Ltd, London.

[29] Kanner, A.M. and Palac, C. (2000) Depression in Epilepsy: A Common but Often Unrecognized Comorbid Malady. Epilepsy \& Behaviour, 1, 37-51. https://doi.org/10.1006/ebeh.2000.0030

[30] Besag, F.M. (1998) Lamotrigine in the Treatment of Epilepsy in People with Intellectual Disability. Journal of Intellectual disability and Research, 42, 50-56.

[31] Brodie, M.J., Richens, A. and Yuen, A.W. (1995) Double-Blind Comparison of Lamotrigine and Carbamazepine in Newly Diagnosed Epilepsy: UK Lamotrigine/Carbamazepine Monotherapy Trial Group. Lancet, 345, 476-479. https://doi.org/10.1016/S0140-6736(95)90581-2

[32] Jr. Engel, J. (1996) Surgery for Seizures. New England Journal of Medicine, 334, 647-652. https://doi.org/10.1056/NEJM199603073341008

[33] Cherian, P.J. (2002) Radhakrishnan K Selection of Ideal Candidates for Epilepsy Surgery in Developing Countries. Neurology India, 50, 11-16.

[34] Beghi, E. and Perucca, E. (1995) The Management of Epilepsy in the 1990s: Acquisitions, Uncertainties and Priorities for Future Research. Drugs, 49, 680-694. https://doi.org/10.2165/00003495-199549050-00004 
[35] Imam Sjahrir, M. (1996) Anti-Epileptic Drug Usage Pattern in Surabaya. Neurology Journal of Southeast Asia, 1, 71.

[36] Remy, C. (1994) Clobazem in the Treatment of Epilepsy: A Review of the Literature. Epilepsia, 35, S88-S91. https://doi.org/10.1111/j.1528-1157.1994.tb05978.x

[37] Khulbe, P. and Juyal, V. (2011) Vinpocetine: A Step towards Memory Enhancement. International Journal of Pharma Research and Development, 2, 99-108.

[38] Nowack, W.J. (2006) Psychiatric Disorders Associated with Epilepsy. E-Medicine Lecture.

[39] Manchanda, R., Schaefer, B., McLachlan, R.S., Blume, W.T., Wiebe. S., Girvin, J.P., Parrent, A. and Derry, P.A. (1996) Psychiatric Disorders in Candidates for Surgery for Epilepsy. Journal of Neurology, Neurosurgery, \& Psychiatry, 61, 82-89. https://doi.org/10.1136/jnnp.61.1.82

[40] Tarulli, A., Devinsky, O. and Alper, K. (2001) Progression of Postictal to Interictal Psychosis. Epilepsia, 42, 1468-1471. https://doi.org/10.1046/j.1528-1157.2001.10701.x 